\title{
THE IMPACT OF IMPLANT NUMBER ON CLINICAL AND RADIOGRAPHIC OUTCOMES OF IMPLANT-SUPPORTED MAXILLARY OVERDENTURE WITH LOCATOR ATTACHMENTS: 2-YEARS OUTCOMES
}

\author{
Mostafa Helmy Mostafa*, Enas Anter Abd El Ghaffar** and Enji Ahmed Mahmoud****
}

\begin{abstract}
Statement of problem: Patient perspectives on the treatment options for maxillary edentulism, which debate include fixed or removable implant-supported prostheses, may help eliminate current uncertainty as to the best choice of treatment plan.

Purpose: This study intended to evaluate the impact of implant number placed in fully edentulous maxilla on the clinical as well as the radiographic outcomes of implant-supported maxillary overdentures with locator attachments over two years of investigation.

Materials \& methods: For this clinical research study held between May 2015 and May 2017, twenty-four fully edentulous patients received new maxillary and mandibular complete dentures prior to implant placement. After common denture delivery modifications, every patient was instructed to use the denture in a conservative manner for three months, with a follow-up appointment every two week. During this period, arrangements for implant placement were processed. Following the three months of adaptation; patients were randomly categorized into two main groups: In the first group (of twelve patients), every patient received six implants in the maxilla (three in each quadrant) utilizing a pre-fabricated computer-aided surgical stent. In the second group (of twelve patients), every patient received four implants in the maxilla (two in each quadrant) utilizing a pre-fabricated computer-aided surgical stent. After six months of implants placement (to ensure complete implants osseointegration), patients of the two groups had completed the procedures of fabricating Implantsupported maxillary overdenture with locator attachment. the clinical \& the radiographic outcomes of the Implants supporting the overdentures had been calibrated at time of implants insertion, 6 months, 12 months, 18 months and 24 months respectively. Noting that: Forcemeter measurements started at the time of overdenture insertion Not at the time of implants insertion (i.e. only four readings were obtained).
\end{abstract}

\footnotetext{
* Lecturer of Removable Prosthodontics, Faculty of Dentistry, Cairo University

** Lecturer of Radiology, Faculty of Dentistry, Cairo University

*** Associate Professor of Oral Medicine and Periodontology. Cairo University
} 
Results: Repeated measures ANOVA test was used to study the changes by time inside each group as well as to compare between the two groups. Moreover, Student's t-test was used to compare between quantities of bone loss or improvement in the two groups. Those studies exhibited that; there was a statistically significant difference in clinical \& radiographic outcomes between the two groups of study throughout the investigation period.

Conclusion: Maxillary Overdentures supported by six implants exhibited a more reliable and better treatment option than those supported by only four implants, in terms of clinical as well as radiographic outcomes.

KEYWORDS: Overdenture, Edentulism, Clinical outcome, Implant Number, Maxillary Denture, Locators.

\section{CLINICAL IMPLICATIONS}

Completely edentulous patients often have problems with their complete dentures; a treatment modality of using four to six implants to support a maxillary overdenture has been proposed to improve the retention as well as the stability of the maxillary denture, in addition to preserving the residual alveolar bone.

\section{INTRODUCTION}

Placement of four to six implants to support a maxillary denture was reported to provide better denture support and prevent overdenture rotation during function. Moreover, it improved comfort and masticatory performance in a way like fixed prostheses, but with more hygienic, aesthetic and cost advantages. ${ }^{[1,2]}$

Systematic reviews comparing implantsupported overdentures retained by utilizing a wide range of attachment mechanisms were recently published. ${ }^{[3-5]}$

The implant-supported treatment modality might be in the form of splinted implants (e.g. barretained overdentures), or unsplinted implants (as in case of ball, locator or magnetic attachments). Owing to the smaller space requirements, ease of cleaning, more economical achievement and lower technique sensitivity; unsplinted attachments have been preferred over splinted ones. ${ }^{[6-8]}$

Design of any overdenture attachment system should provide optimum force distribution around the implants to permit bone loading within the physiological limits. Several in vitro studies reported lower stresses around unsplinted implants utilizing locator attachments. ${ }^{[9-12]}$

Locators attachments presented the lowest profile of the currently available stud attachments. Moreover, they offer simplicity as well as modest space requirements. Furthermore, they provide a dual retention (obtained from the inner and outer contact surfaces between their male and female portions) and finally; easy handled by the patient with less cost effectiveness. ${ }^{[13]}$

Most of clinical studies on maxillary implantassisted overdentures recommended the use of a minimum four to six implants to support the overdenture. Although, there is a controversy about the optimum number of implants that should be inserted to support a maxillary overdenture. Some practitioners believed that using more implants will result in better treatment outcomes, but supporting evidence is still lacking. ${ }^{[14-16]}$

There is also a lack of randomized controlled trials (RCTs) to compare the outcome of specific questions related to the number of implants or design of the superstructure 
Recent systematic reviews, evaluated maxillary implant-supported overdentures with emphasis on the number of implants and anchorage design. They concluded that; four implants were the minimum number that should be utilized to support a maxillary overdenture and recommended six implants in case of compromised bone quality and/or quantity. ${ }^{[17]}$

The aim of this clinical study was to evaluate and compare the effect of two treatment modalities of maxillary implant-supported overdentures in terms of clinical and radiographic outcomes. The first modality utilized six implants to support a maxillary overdenture with locator attachment, while the second modality utilized four implants to support a maxillary overdenture with locator attachment.

The null hypothesis was that there will be no significant difference in outcomes between the two modalities, over the whole investigation period.

\section{MATERIALS AND METHODS}

Twenty-four patients were carefully chosen from the outpatient clinic of the Removable prosthodontics department, Faculty of Dentistry, Cairo University. Where, patient selection was conducted according to the following criteria:

- $\quad$ Age ranged between 40-50 years.

- Patients with completely edentulous arches (mandible \& maxilla). (Fig. 1)

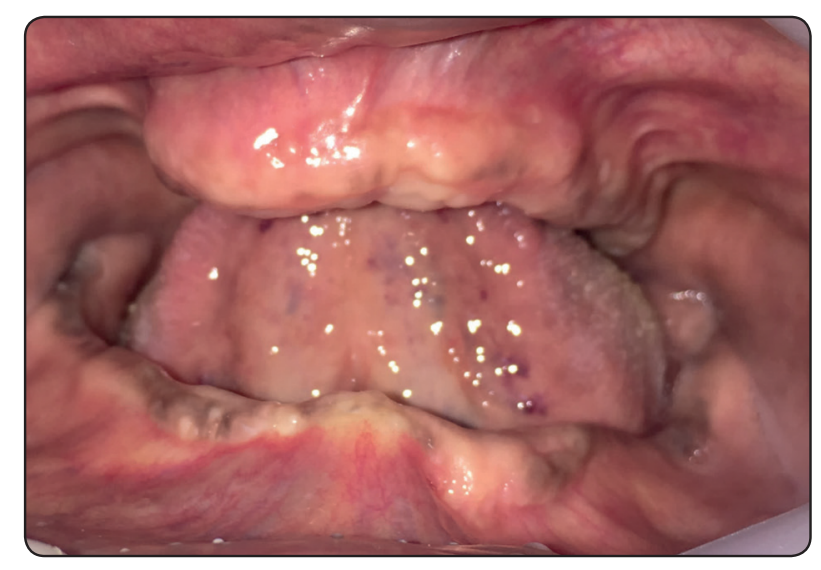

Fig. (1): A patient with completely edentulous arches (mandible \& maxilla).
- Patients with good oral hygiene.

- Patients free from bad oral habits, where patients with tempro-mandibular joint troubles will be excluded.

- Patients free from any systemic or debilitating diseases such as diabetes mellitus, bone diseases or any other diseases that might affect bone healing around the implants.

- Absence of any medical disorder that might obscure the surgical phase or disturb osseointegration.

- Patients exhibited sufficient inter-arch space (at least $13 \mathrm{~mm}$. from the mandibular ridge to the occlusal plane).

- Patients with Angle's class I maxillo-mandibular relationship with normal occlusion.

- Heavy smokers (more than 20 cigarettes per day), were excluded from this study.

- Uncooperative patients were omitted, only cooperative patients were included in the study

The patients were asked for their approval to the conduction of the research \& being recalled for follow-up appointments. All details were written \& signed by the patients in consent forms.

The study was conducted according to principles stated in Helsinki Declaration \& being approved by the Faculty ethical committee.

After taking full patient's personal, medical and dental history, each patient received a thorough clinical and radiographic examination.

\section{Construction of the complete dentures prior to surgery:}

- Maxillary and mandibular primary impressions were made utilizing irreversible hydrocolloid impression material* according to the 
manufacturer's instructions and poured into stone plaster** to obtain diagnostic casts over which acrylic resin*** special trays were fabricated.

- For every patient, the casts were mounted on a simple hinge articulator aided by a tentative inter-occlusal wax record. Afterwards, the occlusal relation between the maxillary and mandibular teeth was thoroughly examined.

- Final impressions were made by two-step rubber base impression material $* * * *$ according to the manufacturer's instructions.

- Master casts were obtained, Occlusion blocks were constructed, and centric jaw relation was recorded using the traditional check-bite method.

- Occlusion blocks on their master casts were mounted on semi-adjustable articulator*****, where, the maxillary cast was mounted according to a face bow record \& the mandibular cast was mounted by the aid of the recorded centric jaw relation record.

- Following setting-up of teeth, try-in stage was carried out in the usual manner. When assuring satisfactory Try-in, the dentures were completed till obtaining the final maxillary \& mandibular complete dentures following the traditional steps of construction.

* Patients were asked to utilize their dentures for three months of adaptation with recall appointment every two weeks for denture assessment \& any needed occlusal refinement.
* It is worth to clarify that all dentures were fabricated by the same dental technician in the same laboratory.

\section{Construction of the radiographic template:}

- On the cast, all undercuts were blocked out using modelling wax******, and the cast was painted with a separating medium. A self-cured acrylic resin was mixed and applied at dough stage on the stone cast to cover the edentulous areas.

- A Rinn XCP Anterior and Posterior bite blocks******* were hard-pushed on the acrylic resin with the film backing plate parallel to the long axis of the implants \& then the acrylic resin was presented inside the side holes of the bite block.

- The templates were finished, polished and tried in the patient's mouth to test its precision and to adjust any overextension or pressure areas that might disturb accurate fitting of the template.

- The acrylic templates were reserved in water to be used throughout the follow-up periods.

- Standardization of imaging using long cone paralleling technique was performed.

\section{Patient imaging and case planning:}

* At this stage; the patients were randomly divided (blind randomization) into two equal groups (twelve patients/each), the first group (G.I) received six implants in maxilla, while the second group (G.II) received four implants in maxilla.

\footnotetext{
*Cavex alginate, dust free, high consistency, Holland.

**Type III dental stone Lascod SP, sestofino, Italy.

***Moldano. Bayer Leverkusen, pekatray, Germany.

**** Elite HD, Zermack, Italy.

$* * * * *$ Bio-art articulator 5000, Brazil

$* * * * * *$ Cavex, Harlem, Holland.

******* Rinn Corporation, XCP instruments for extension cone paralleling technique.
} 
* Duplication of the maxillary complete denture was encountered utilizing a radio-opaque material* to construct radiographic stents for every patient.

* Patients were imaged using cone beam computed tomography scans (CBCT scans) through a cone beam CT machine (CBCT, i-CAT Vision) $* *$. Each patient was instructed to bite on a piece of cotton to achieve adequate jaw separation, with their heads adjusted with the help of laser beam indicators, so that; the midsagittal plane is perpendicular to the floor \& the occlusal plane is parallel to the floor.

* Finally, the resultant image was obtained as $a$ DICOM file. Then, the images were processed using specialized image processing software (Blue Sky implant software) $* * *$.

\section{Surgical guide fabrication:}

virtual implants were placed in their predetermined positions in the maxilla. Then, a solid block was modeled \& guiding holes denoting the implant direction were opened into the block. The final virtual guide was exported as an STL file to be prototyped using a 3D printer****. The obtained guide was modified by inserting specially designed metallic sleeves to accommodate the drills.

\section{Pre-surgical steps:}

the surgical stent was sterilized chemically***** to be used during surgery.

\footnotetext{
* Barium sulphate disilicate.

** Imaging Sciences International, Hatfield, Pa, USA.

*** Blue Sky Bio, LLC

***** Invision Si2, USA.

***** Micro 10, A.B. Pharma, Switzerland.

******* Augmentin 625mg Beecham, MUP.

$* * * * * * *$ Listerine mouthwash.

$* * * * * * * *$ Betadine solution, El Nil.

********** Ubestesin, 3M ESPE, Germany.

$* * * * * * * * * *$ Cleanlant, Dentis Implant Equipment, Korea.
}

The patient was instructed to take a prophylactic antibiotic preoperatively****** and to rinse with chlorohexidine mouth wash $* * * * * * *$ four hours before surgery.

\section{Surgical Procedures}

Two-stage surgery was followed, and the patients could wear their dentures during the healing period in-between:

The entire surgical armamentarium was autoclaved.

The patient was asked to gargle with chlorohexidine mouth wash.

The surgical place as well as the circumoral tissues were also disinfected by wiping them with antiseptic solution $* * * * * * * *$.

An infiltration anaesthesia was given at the surgical sites using 4\% articaine anesthetic solution*********. In addition, field block anaesthesia was applied to diminish the bleeding as much as possible.

- The surgical template was introduced into the patient's mouth, seated over the maxilla and checked for accuracy \& stability in place.

- Osteotomy sites for the 6 implants (in Group One, G. I) and the 4 implants (in Group Two, G. II), were performed using a series of specialized computer-guided drills***********. For each drill, a specially designed "drill guide" was used. The drill guide is a cylinder with a short 
handle. The thickness of the handle was $1 \mathrm{~mm}$. The outer diameter of the drill guide fitted accurately within the metal sleeves fixed into the stent.

\section{Implant insertion:}

- The sterile box of the implant* was unwrapped, and then the inner vial was also opened.

- The sterile implant was introduced into its site by screwing it using moderate finger pressure [selftapping] Once resistance was felt, the abutment was unscrewed from the implant fixture \& the ratchet wrench was adapted to the implant and the screwing process was continued.

- The screwing process was stopped when the implant becomes flushed with the crest of the bone or preferably $0.5 \mathrm{~mm}$ below the crestal bone level. The universal hex driver was then introduced to install the covering screw onto the implant in a clock wise direction.

\section{Post-Surgical Instructions}

The patients were immediately given an antiinflammatory analgesic tablets (Voltaren $75 \mathrm{mg}$ ) **, and were advised to follow the antibiotic regimen previously prescribed for 5-7 days. Patients were given the following instructions:

- To apply ice packs for 10 minutes with 10 minutes intervals along a period of 3-4 hours immediately following surgery.

- To follow strict oral hygiene protocol.

- Not to wear the denture for 10 days, then asked for a recall appointment after 10 days to relive the fitting surface of the denture with application of soft liner***.
- Only soft diet is allowed for one month.

- Asked for a recall appointment after six months, to complete the restorative procedures.

\section{Phase of Restoration:}

After six months, the patients were checked for maintaining the oral hygiene measures and then starting the restorative phase of treatment.

A post-operative Panoramic radiograph was made for the implant to ensure osseointegration.

- Infiltration anaesthesia was given at the surgical site \& a probe was used to determine the exact position of the head of the implant guided by the surgical template (if the implant covered by gingival tissue).

- The universal hex driver was used to unscrew the covering screw of the implant. The gingival former was then introduced, fixed onto the implant using the universal hex driver. Then, left in the patient's mouth for 2 weeks to obtain the normal gingival contour.

- Patients were then recalled, unscrewing the gingival former and measuring the transmucosal tissue height in order to choose the correct Locator Abutment height (should be $2 \mathrm{~mm}$ above the gingiva). Meanwhile, second clinical \& radiographic readings of the installed implants were tabulated.

- Locator abutments were then, mounted in the internal hex of the implants using the insertion key tool, tightened by the torque rench $(35 \mathrm{~N}$ torque).(Fig. 2)

- Patients of both groups received their overdenture through indirect (laboratory) pickup technique: (Fig. 3-5)

\footnotetext{
* Osstemm Dental Implant, Hiossen dental, Kore.

** Voltaren, $75 \mathrm{ml}$ oral, NOVARTS, Egypt.

*** GC Corporation, Tokyo, Japan.
} 


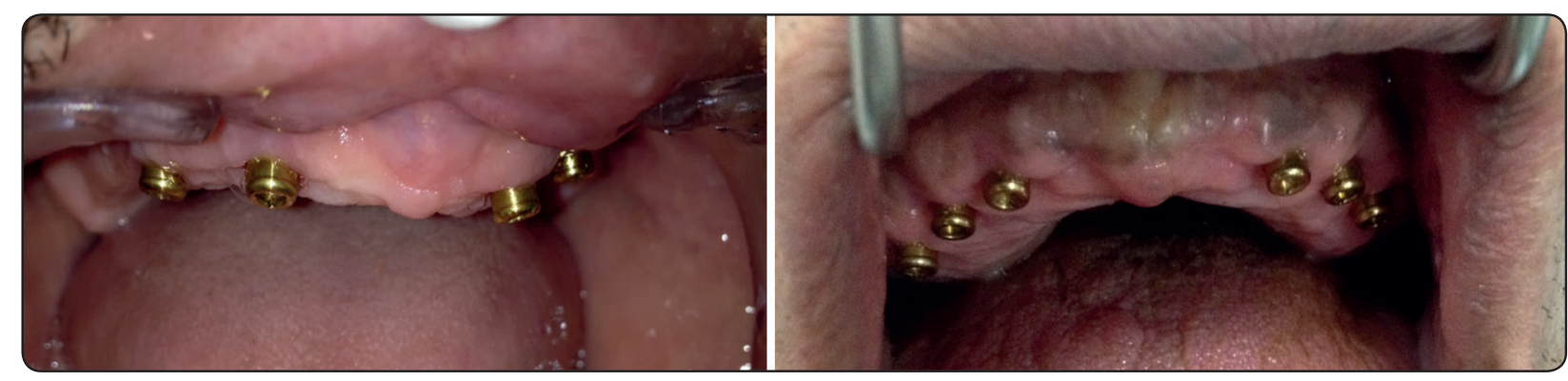

Fig. (2) Locator abutments properly tightened onto corresponding implant fixtures.
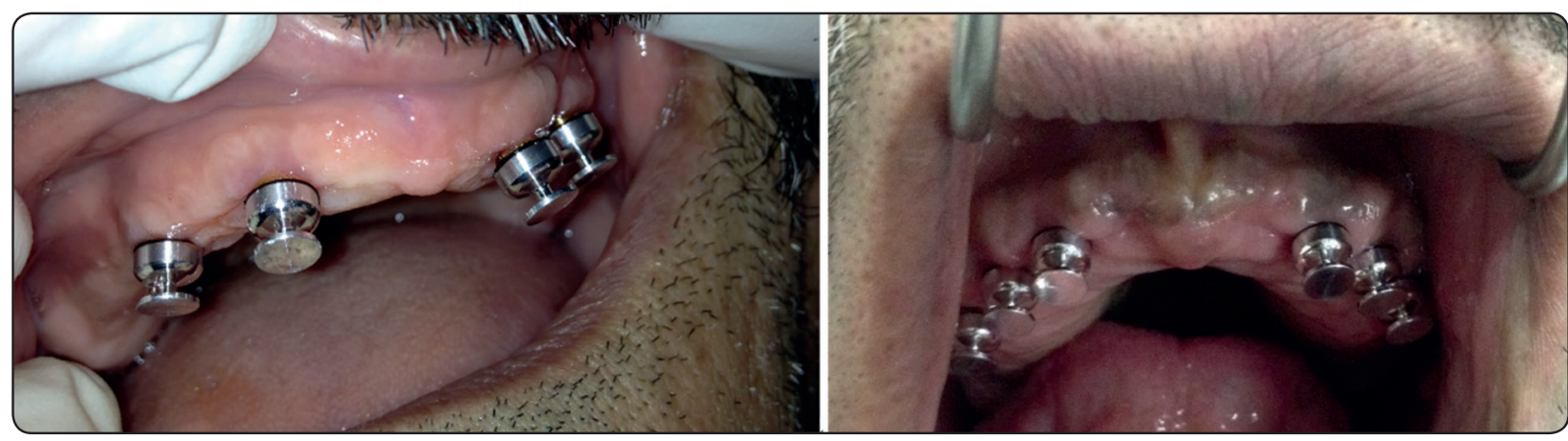

Fig. (3) Metal transfer copings suitable fitted on their corresponding abutments.

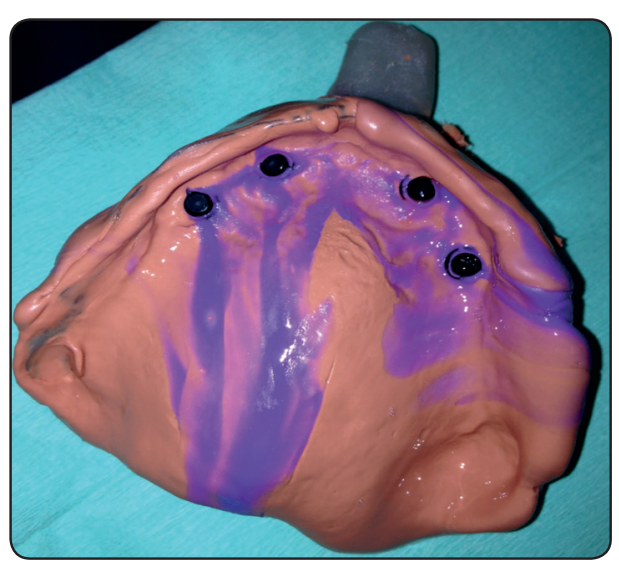

Fig. (4): A one-step rubber base impression including the metal transfers.

Maxillary and mandibular primary impressions were made utilizing irreversible hydrocolloid impression material was made to obtain primary casts. Over the maxillary cast, a spacer was adapted, and a custom-made acrylic resin tray was fabricated.
Metal transfer copings suitable for the used locator abutments were press-fitted on their corresponding abutments.

The custom-made acrylic resin tray was painted by rubber base adhesive then loaded by heavybody rubber base impression material. Meanwhile, A light-body rubber base impression material was injected around the locator abutment with their corresponding metal transfers. A one-step rubber base impression was taken.

After setting, the maxillary impression was then removed from patient's mouth, checked for accuracy \& presence of the metal transfers inside the impression. Abutment analogues were then accurately positioned into their corresponding metal copings.

In the laboratory, the impression was poured utilizing extra-hard stone to obtain a cast that exhibited the locator abutment analogues over which the metal transfers were present. 


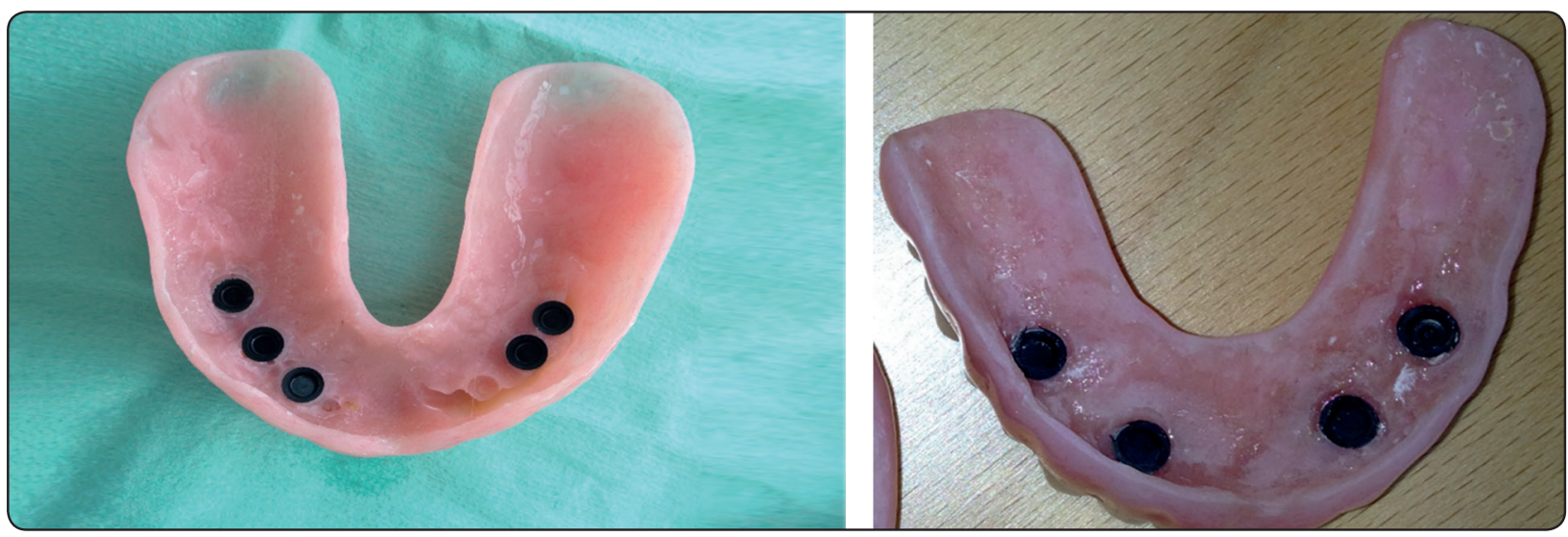

Fig. (5) Finished and polished overdenture containing the male patrices with Black processing nylon inserts.

Maxillary \& mandibular casts with their corresponding dentures are mounted on a semiadjustable articulator by the aid of the previouslyrecorded face-bow record \& an inter-occlusal centric jaw relation record.

The white locator blocking rings (which block the undercut) were stretched over the locator abutments analogues, followed by inserting the metal housings with the black processing nylon inserts directly over their corresponding abutments. The fitting surface of the maxillary denture opposite to the abutments analogues was marked by the aid of an indelible pencil, the markings are then relived (deepened) and widened mesio-distally. In addition, tiny holes were made in the palatal surface of the denture for easy escapement of excess acrylic resin material during the indirect pick-up procedure. The denture was checked for complete seating above the housings before completing the pick-up procedures. The denture was then dried \& the relieved areas were slightly coated with acrylic resin monomer.

Mixing of sufficient amount of chemically-cured acrylic resin was then made, inserted in the relieved areas of the denture fitting surface $\&$ the denture was placed accurately in position to perform an indirect pick-up of the metal housings while the articulator was closed in centric position.
After setting of the acrylic resin, the denture was gently removed from the maxillary cast, checked that all metal housings were picked up into its fitting surface. Finishing \& polishing of the denture was then applied, and the processing black nylon inserts were replaced by pink nylon inserts (of medium retention values) by the aid of the insertion key.

An added step was performed, were the palatal portion of the maxillary denture was cut off i.e. a horse-show shaped maxillary denture was obtained.

The denture was then delivered to the patient, checked for accuracy \& complete non-endured seating. (Fig. 6)

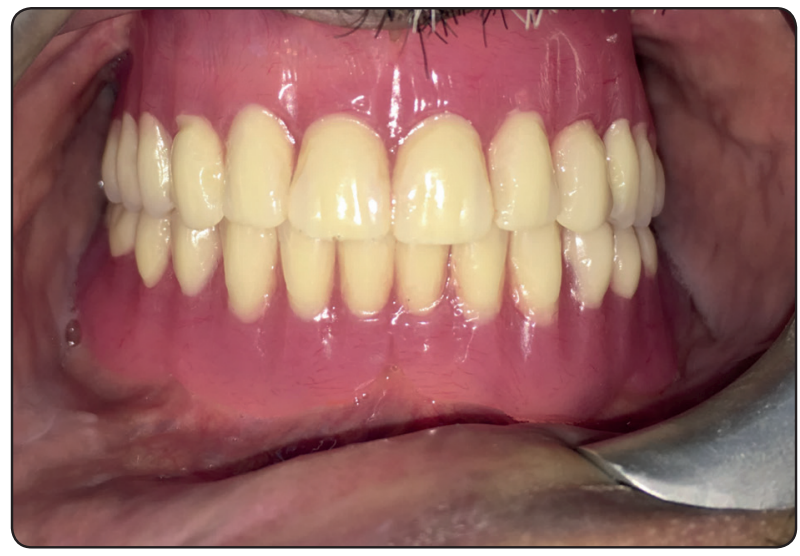

Fig. (6): Finished \& polished implant-supported overdenture accurately placed in patient's mouth. 


\section{Final adjustments \& follow-up:}

After denture insertion and training the patient on easy insertion \& removal of the denture; patients were instructed to follow strict oral hygiene measures and asked for a recall appointment every single week in the first 4 weeks for any required denture adjustments \&/or refinement of occlusion.

\section{Clinical evaluation:}

This included the following:

\section{Osstell Measurements;}

A specially designed measuring tool termed "Smart Peg"* was inserted with a special plastic cap (to measure the Implant Stability Quaint, ISQ), screwed into the internal surface of the implant. Then, utilizing the frequency transducer device "Osstell" **, four readings (buccal, lingual, mesial $\&$ distal) were obtained for each implant. Mean of the 4 readings will represent the ISO of that implant.

The procedure was repeated in other implants and finally, the mean of all implants ISQ was utilized to represent the mean Osstell reading in that stage.

Measurements were made at time of implants insertion, 6 months, 12 months, 18 months and 24 months respectively.

\section{Forcemeter Measurements}

Retention of the implant-supported overdenture was measured by using a Digital Forcemeter; by the aid of (A Retention-Aided Measuring Device), for accurate reproducible measurement \& ensuring equal distribution of the dislodging forces over the whole overdenture surface.

Measurements were made at time of overdenture insertion, 6 months, 12 months and 18 months respectively.
Every patient was instructed to sit in the dental chair, so that the occlusal plane of the maxillary teeth was parallel to the floor. Patients were asked to fix their heads during the steps of examination.

The maximum force of vertical dislodgment in Newtons (N) was calculated; each measurement was repeated three times, and the mean retention value was calculated.

* It is worth to clarify that the pink nylon inserts of the overdentures of all patients were replaced by new ones of the same color after 12 months of placement.

\section{B) Radiographic evaluation:}

Direct digital radiography utilizing the Digora computerized system* was applied for making intraoral digital radiographic images to assess the following:

1- Changes in the mesial and distal marginal bone height around the implants.

2- Changes in bone density around the implants.

- The imaging plate was introduced into a protective bag which was sealed by the Digora system. The stored images of every single patient were interpreted at the end of the follow up period. Digital images were made for the implants, immediately following their insertion, six months later and then every passing six months of the successive two years.

\section{Image analysis:}

The Digital images were used to analyze and evaluate the following:

\section{a) Marginal bone height measurements (linear analysis):}

Implant measurements were made as follow: The distance from the shoulder of the implant to the 
crest of the alveolar ridge, where a line was drawn tangential to the implant and parallel to its long axis. The mean value of both mesial and distal readings was taken, tabulated and statistically analyzed.

The procedure was repeated in other implants and finally, the mean of all implants measurements was utilized to represent the mean bone height reading in that stage.

The increase in the marginal bone height measurements denotes bone resorption.

\section{b) Measurements of bone density (Radiometric/ Densitometric analysis):}

The Digora system software was utilized for assessment of the changes in bone density mesial $\&$ distal to each implant. The measurements were as follows: Two lines were drawn; the first line extended mesial to the implant from the shoulder of the implant to the apex of the implant and parallel to its long axis, while the second line extended distal to the implant from the implant shoulder to its apex. Bone density alongside each of the two lines was documented and then the mean value of both readings was calculated for further assessment.

The procedure was repeated in other implants and finally, the mean of all implants measurements was utilized to represent the mean bone density measurement in that stage

* Patients of both groups were asked for recall appointments every six months, following overdenture insertion till 2 years of implants insertion for measuring the clinical and radiographic outcomes.

* All the results were calculated, tabulated and then statistically analyzed.

\section{Statistical analysis:}

Data were presented as means and standard deviation (SD) values.

\section{Statistical tests:}

The data was expressed as means \pm standard deviations and mean percentage changes.

Repeated measures ANOVA test was used to study the changes by time within each group as well as to compare between the two groups. Bonferroni's post-hoc test was used for pair-wise comparisons when ANOVA test is significant.

Student's t-test was used to compare between amounts of bone loss or gain in the two groups.

\section{Significance level:}

The significance level was set at $\mathrm{P} \leq 0.05$. Statistical analysis was performed with IBM, SPSS** Statistics Version 20 for Windows.

\section{RESULTS}

Numerical data were searched for normality by examining the data spreading and using Kolmogorov-Smirnov and Shapiro-Wilk tests. All data exhibited normal (parametric) distribution.

Repeated measures ANOVA test was utilized to elaborate the changes by time inside each group as well as to compare between the two groups. Bonferroni's post-hoc test was utilized for pairwise comparisons when ANOVA test is significant. Student's t-test was operated to compare between values of bone deficiency or improvement in the two groups.

The significance level was customized at $\mathrm{P} \leq$ 0.05. Statistical assessment was achieved with IBM $^{\circledR}$ SPSS $^{\circledR}$ Statistics Version 20 for Windows.

\footnotetext{
* Orion corporation, Soredex, Finland.

** SPSS, Inc., Chicago, IL, USA.
} 
Osstell measurement Fig. 7, Table (I):

\section{In both groups:}

A statistically significant decrease in mean measurement after 6 months was observed.

From 6 months to 12 months; there was a statistically significant increase in mean Osstell measurement.

From 12 months to 18 months as well as from 18 months to 24 months; there was no statistically significant change in mean Osstell measurement.

There was no statistically significant difference between Osstell measurements from the base line till 24 months.

Retention (Forcemeter) measurement Fig. 8, Table II:

Comparison between the two groups; revealed that (Group I) showed statistically significantly higher mean retention value than (Group II) at time of overdenture insertion, after 6 months, 12 months as well as 18 months.

\section{Changes by time within both groups;}

There was non- statistically significant decrease in mean retention values after 6 months.

From 6 months to 12 months; there was a statistically significant decrease in mean retention values.

From 12 months to 18 months; there was a statistically significant increase in mean values.

\section{Bone height measurement Fig. 9Table III, IV):}

\section{Changes by time inside each group;}

For (Group I); A statistically significant increase in mean bone height measurements was detected after 6 months. From 6 months to 12 months; there was a statistically significant decrease in mean bone height measurements. From 12 months to 18 months as well as from 18 months to 24 months; A non-statistically significant change in mean values was detected.

For (Group II); A statistically significant increase in mean bone height values was observed after 6 months. From 6 months to 12 months; A non-statistically significant change in the mean bone height measurements. From 12 months to 18 months as well as from 18 months to 24 months; there was a statistically significant increase in the mean values.

Comparison between amounts of bone loss or gain in the two groups; revealed that after 6 months; (Group I) showed statistically significantly lower amount of bone loss than (Group II). From 6 months to 12 months; (Group I) showed statistically significantly increased mean bone formation values than (Group II). From 12 to 18 as well as from 18 to 24 months; (Group II) showed statistically significantly higher mean amount of bone loss than (Group I), where (Group I) exhibited greater bone formation.

Bone density Fig. (10)- (Table (V):

\section{Changes by time inside each group;}

For (Group I); A statistically significant decrease in mean bone density values was observed after 6 months. Whilst, from 6 months to 12 months; there was a statistically significant increase in the mean bone density measurements. From 12 months to 18 months; there was no statistically significant alteration in the mean values. From 18 months to 24 months; there was a statistically significant rise in the mean bone density.

The mean bone density following two years revealed non-statistically significant change from the insertion measurement.

For (Group I); A statistically significant decrease in the mean bone density values was detected after 6 months. Whereas, from 6 months to 12 months, 12 months to 18 months as well as 18 months to 
24 months; A non-statistically significant change in mean bone density measurements was observed. However, the mean bone density after 24 months exhibited statistically significantly decreased value than the insertion value.

Comparison between the two groups; revealed that at insertion as well as after 6 months; there was no statistically significant variation between both groups.

After 12 months, 18 months as well as 24 months; (Group I) exhibited statistically significant higher mean bone density measurements than (Group II).

TABLE (I): The mean, standard deviation (SD) values and results of repeated measures ANOVA test for comparison between Osstell measurements at different time periods:

\begin{tabular}{|c|c|c|c|c|c|c|c|c|c|c|}
\hline \multicolumn{2}{|c|}{ Base line } & \multicolumn{2}{c|}{6 months } & \multicolumn{2}{c|}{12 months } & \multicolumn{2}{c|}{18 months } & \multicolumn{2}{c|}{24 months } & \multirow{2}{*}{$P$-value } \\
\cline { 1 - 7 } Mean & SD & Mean & SD & Mean & SD & Mean & SD & Mean & SD & \\
\hline $76.5^{\mathrm{A}}$ & 3.1 & $70.3^{\mathrm{B}}$ & 3.9 & $80.0^{\mathrm{A}}$ & 1.1 & $78.2^{\mathrm{A}}$ & 3.0 & $75.7^{\mathrm{A}}$ & 1.9 & $<0.001^{*}$ \\
\hline
\end{tabular}

* Significant at $P \leq 0.05$, Different superscripts are statistically significantly different

TABLE (II): The mean, standard deviation (SD) values and results of repeated measures ANOVA test for comparison between retention values in the two groups as well as changes by time within each group:

\begin{tabular}{|c|c|c|c|c|c|}
\hline \multirow[t]{2}{*}{ Group } & \multicolumn{2}{|c|}{ Group I } & \multicolumn{2}{|c|}{ Group II } & \multirow{2}{*}{$\begin{array}{c}P \text {-value } \\
\text { (Between groups) }\end{array}$} \\
\hline & Mean & SD & Mean & SD & \\
\hline At overdenture insertion & $61.3^{\mathrm{A}}$ & 1.5 & $52.3^{\mathrm{A}}$ & 3.1 & $0.005^{*}$ \\
\hline 6 months & $57.3^{\mathrm{A}}$ & 1.0 & $48.8^{\mathrm{A}}$ & 2.5 & $<0.001^{*}$ \\
\hline 12 months & $50.9^{\text {в }}$ & 0.9 & $40.1^{\text {в }}$ & 4.3 & $<0.001^{*}$ \\
\hline 18 months & $60.0^{\mathrm{A}}$ & 1.1 & $47.9^{\mathrm{A}}$ & 3.0 & $<0.001 *$ \\
\hline$P$-value (Within group) & \multicolumn{2}{|c|}{$<0.001 *$} & \multicolumn{2}{|c|}{$0.001 *$} & \\
\hline
\end{tabular}

* Significant at $P \leq 0.05$, Different superscripts in the same column are statistically significantly different

TABLE (III): The mean, standard deviation (SD) values and results of repeated measures ANOVA test for comparison between bone height measurements at different time periods within each group:

\begin{tabular}{|c|c|c|c|c|}
\hline \multirow{2}{*}{ Time Group } & \multicolumn{2}{|c|}{ Group I } & \multicolumn{2}{c|}{ Group II } \\
\cline { 2 - 5 } & Mean & SD & Mean & 0.59 \\
\hline At insertion & $5.85^{\mathrm{B}}$ & 0.61 & $4.44^{\mathrm{D}}$ & 0.68 \\
\hline 6 months & $6.33^{\mathrm{A}}$ & 0.70 & $5.30^{\mathrm{C}}$ & 0.72 \\
\hline 12 months & $5.34^{\mathrm{C}}$ & 0.69 & $5.15^{\mathrm{C}}$ & 0.60 \\
\hline 18 months & $5.21^{\mathrm{C}}$ & 0.62 & $5.52^{\mathrm{B}}$ & 0.89 \\
\hline 24 months & $5.11^{\mathrm{C}}$ & 0.76 & & \\
\hline
\end{tabular}

* Significant at $P \leq 0.05$, Different superscripts in the same column are statistically significantly different 
TABLE (IV): The mean, standard deviation (SD) values and results of Student's t-test for comparison between amounts of bone loss (or gain) in the two groups:

\begin{tabular}{|c|c|c|c|c|c|}
\hline \multirow{2}{*}{ Time Group } & \multicolumn{2}{|c|}{ Group I } & \multicolumn{2}{c|}{ Group II } & \multirow{2}{*}{$P$-value } \\
\cline { 2 - 6 } & Mean & SD & Mean & SD & \multirow{2}{*}{$0.040^{*}$} \\
\hline \multirow{2}{*}{ At insertion - 6 months } & -0.48 & 0.15 & -0.86 & 0.09 & $<0.001 *$ \\
\hline 6 months - 12 months & 0.99 & 0.15 & 0.15 & 0.03 & $<0.001 *$ \\
\hline 12 months - 18 months & 0.13 & 0.03 & -0.37 & 0.10 & $<0.001 *$ \\
\hline 18 months - 24 months & 0.10 & 0.03 & -0.49 & 0.11 & $<$ \\
\hline
\end{tabular}

*: Significant at $P \leq 0.05$

TABLE (V): The mean, standard deviation (SD) values and results of repeated measures ANOVA test for comparison between bone density values in the two groups as well as changes by time within each group:

\begin{tabular}{|c|c|c|c|c|c|}
\hline \multirow{2}{*}{ Time Group } & \multicolumn{2}{|c|}{ Group I } & \multicolumn{2}{c|}{$\begin{array}{c}\text { Group II } \\
\text { (Between groups) }\end{array}$} \\
\cline { 2 - 6 } & Mean & SD & Mean & SD & 0.078 \\
\hline \multirow{2}{*}{ At insertion } & $166.6^{\mathrm{A}}$ & 9.1 & $159.6^{\mathrm{A}}$ & 7.2 & 0.642 \\
\hline 6 months & $138.7^{\mathrm{C}}$ & 8.2 & $133.7^{\mathrm{B}}$ & 6.2 & $0.025^{*}$ \\
\hline 12 months & $154.0^{\mathrm{B}}$ & 10.1 & $142.3^{\mathrm{B}}$ & 5.2 & $0.002^{*}$ \\
\hline 18 months & $158.2^{\mathrm{B}}$ & 12.2 & $140.1^{\mathrm{B}}$ & 6.3 & $<0.001^{*}$ \\
\hline 24 months & $170.1^{\mathrm{A}}$ & 8.9 & $138.0^{\mathrm{B}}$ & 7.1 & \multirow{2}{*}{$<0.001^{*}$} \\
\hline
\end{tabular}

* Significant at $P \leq 0.05$, Different superscripts in the same column are statistically significantly different

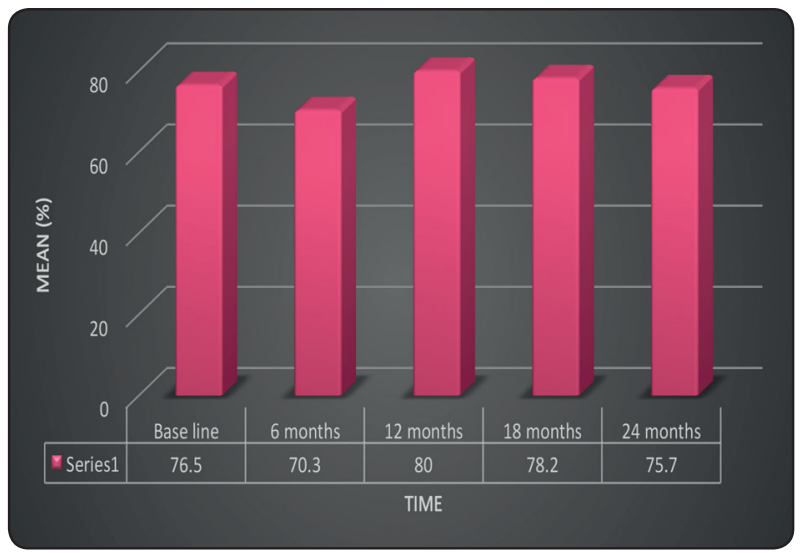

Fig. (7) A chart representing mean values for Osstell measurements at different follow up periods.

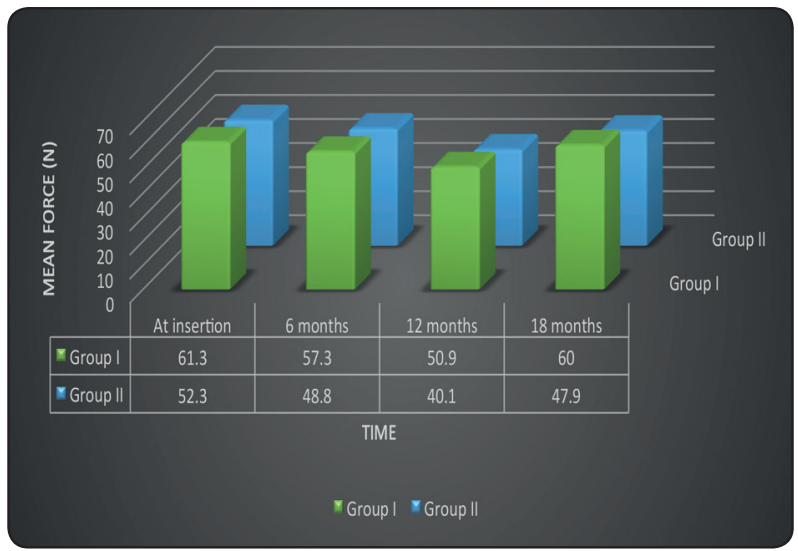

Fig.(8) A chart representing mean retention values in the two groups. 


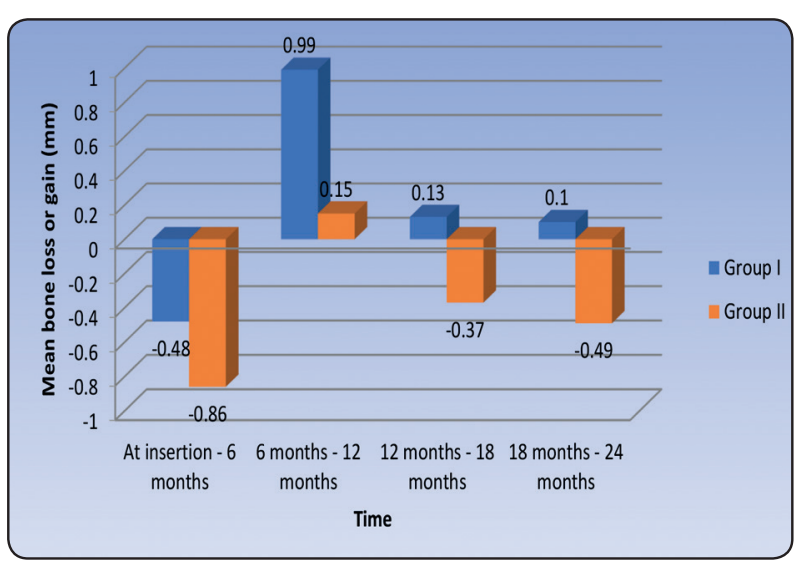

Fig. (9): A chart representing mean amounts of bone loss and gain in the two groups.

\section{DISCUSSION}

\section{Discussion of Methodology}

In this study, all factors that could affect the osseointegration of implants were carefully considered during patient selection and later after restoration. ${ }^{[18]}$

Twenty-four fully edentulous, healthy patients of age ranging from 40-50 years old were included in this study to avoid any fluctuation in bone changes that might affect the obtained results.

Maintenance of good oral hygiene has a great influence on the success of this study to the extent that it has a great impact on the osseointegration process. Strict oral hygiene measures were applied for all patients. ${ }^{[19]}$

Patients exhibited adequate inter-arch space, to ensure adequate room for all the overdenture components without encroachment on the normal vertical dimension of occlusion. ${ }^{[20]}$

Only cases with normal maxilla-mandibular relation were included in the study to avoid the effect of transmission of abnormal forces to the implants. ${ }^{[1]}$

Patients with superior general health were only selected, to avoid the reflection of any systemic

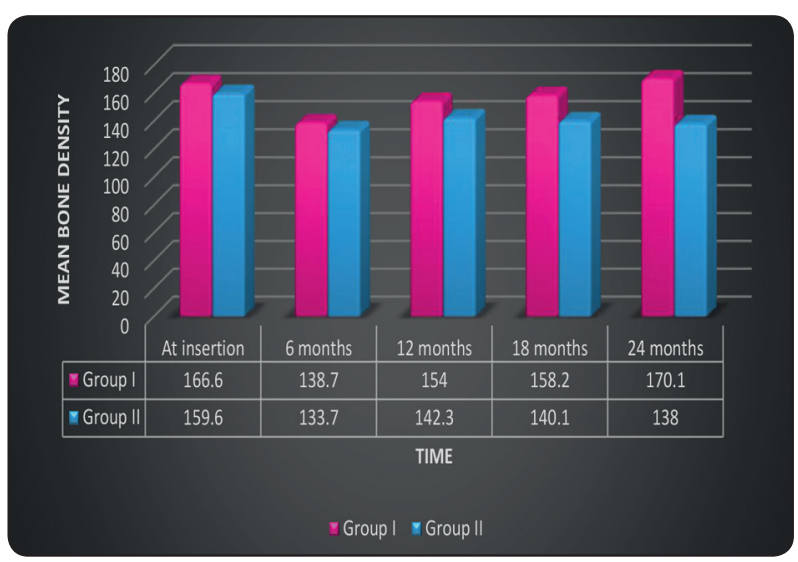

Fig. (10): A chart representing mean bone density measurements in the two groups.

disorder on the bone condition, and hence, osseointegration. ${ }^{[20]}$

Heavy smokers were excluded as smoking is considered as an important factor in early implant failure due to anoxia of the oral cavity, as recommended by several authors. ${ }^{[21]}$

Uncooperative patients were excluded, and only cooperative patients were included in the study to ensure their commitment to the oral hygiene measures and the regular follow up visit.

Bone quality and quantity were evaluated radiographically to ensure primary stability of the implant at the time of its placement. In addition, patients with sufficient Bucco-lingual width at sites of implants placement were only selected to ensure at least one mm. thickness of bone remaining buccal and lingual to the implant after its placement. ${ }^{[22]}$

Inter-occlusal jaw relation record had been made to the patients to ensure an adequate inter-arch space. Moreover, it helped in determination of ridge relationship where patients only with Angle class I were included in the study to facilitate implant insertion and avoid implants overloading. ${ }^{[23]}$.

Construction of a computer-guided surgical stent was carried out, to ensure accuracy of implant placement in the three dimensions as well as decreasing the human interfering factors that might affect the adjustment of implants angulation. ${ }^{[24]}$ 
The difference in diameter between the drills and the drill guide prevented friction between the drill and the sleeve and allowed for penetration of the irrigation with the up and down motion of the drill.

All implants used were threaded, self-tapping, root form implants, $10 \mathrm{~mm}$ length and $4 \mathrm{~mm}$ width. This implant design was used to ensure primary stability during the initial healing period, as well as, increasing the contact area between the implant and the surrounding bone for better osseointegration. ${ }^{25]}$

Panoramic radiograph was the imaging modality of choice in evaluating implants osseointegration, to avoid the metallic artifacts that accompany CBCT (due to presence of multiple implants). ${ }^{[26]}$

A rubber base impression material was utilized to ensure accurate recording of fine details, and hence, obtaining an accurate restoration. ${ }^{[27]}$

Varnishing the impression surfaces surrounding the analogues with Vaseline was carried out in order to facilitate impression removal from the stone cast and ensuring that the implant analogues remain embedded into the stone cast.

The Retention-Aided Measuring Device was utilized to ensure adequate distribution of vertical dislodging forces (exerted by the digital Forcemeter) on the whole overdenture surface; hence, reliable measurements of retention could be gained.

The cases were followed up for two years to ensure proper evaluation of clinical \& radiographic outcomes throughout a suitable period of time.

\section{DISCUSSION OF RESULTS}

This clinical research study evaluated the clinical and radiographic outcomes for implant-supported maxillary overdentures, over two years.

Clinical and Radiographic outcomes for different treatment approaches using oral implants in the edentulous maxilla for overdentures support, are still controversial in prosthetic literatures. This is complexed by the different number of maxillary implants used to support the overdentures.
Oral rehabilitation with implant-supported overdentures in completely edentulous maxillae offers a wide range of treatment modalities not only based on the varying number of implants utilized, but also relied on the variety of different retentive options provided. ${ }^{[28]}$

The management of a completely edentulous maxilla using osseointegrated implants to support a maxillary overdenture with locator attachments represents an accepted treatment modality. However, a controversy exists about the optimum number of implants to be used for such situations. ${ }^{[29-31]}$

From this two-years study, it is concluded that six dental implants evenly distributed in the anterior $\&$ the posterior region of the edentulous maxilla, supporting a maxillary overdenture with locator attachment, and opposed by mandibular denture, provided better support \& retention of the overdenture.

Several studies reported that locator pink inserts recorded the highest initial retention compared to other types of locator attachments. On the other hand, the dual retention property of locator attachment, which comes from friction between inner and outer surface together with limited lateral and hinge movements, may be responsible for transferring more forces to the implants; thus, contributing to the slightly increased bone loss around the implants.

The strict oral hygiene regimen to which patients were subjected to, resulted in healthy peri-implant tissues. During the recall periods of all patients, there were no complaints from the installed implant and all the patients followed the oral hygiene instructions to avoid any harmful effect which might influence the results of this study. ${ }^{[32]}$

The statistically significant decrease in the mean Osstell measurements from base line to six months might be attributed to the inflammatory, resorptive and remodeling activities during the healing process.

These findings were in line with those studies which concluded that; although new implant surface 
and chemistry designs have shortened and improved osseointegration, the initial implant stability drop is still present and remains a challenge for future research and development. ${ }^{[33]}$

Moreover, the mechanism behind the decrease of ISQ during the first six months might be related to the changes of bone-implant interface as well as the properties of the surrounding bone (i.e. the interfacial stiffness). Firstly, the tapered implant creates a lateral compression of the bone tissue during insertion and it is likely that the relaxation of the inbuilt stresses between the implant and bone occurred after implant placement, which can be considered as a decrease in ISQ. Secondly, it can be speculated that loading might induce microfractures in the surrounding bone. These were in line with many similar studies. ${ }^{[34]}$

The statistically significant increase in the mean Osstell measurements from six months to twelve months of prosthesis insertion, indicating the increased amount of bone formation around the implants and hence, greater implant osseointegration. [35]

The statistically significant increase in the mean Osstell measurements from base line to twelve months matched the time frames of bone formation and maturation around the dental implants. ${ }^{[36]}$

Different important factors are involved in overdenture retention, such as muscular retentive forces, forces associated with the attachment system, overdenture supporting area, direction of insertion, and implant angulation. In addition, neuromuscular reflexes develop and are conditioned by the overdenture outline, which enable the patient to tolerate newly designed overdentures after some time, and therefore, improved retention measurements. ${ }^{[37]}$

Both groups exhibited decreased retention values after 12 months of prosthesis function, which might be attributed to wear of the retentive nylon inserts. But, it was found that; after 6 months of clinical use, the range of retention values of locator attachments was still within the accepted range of required retention. ${ }^{[38]}$

The significant decrease in retention of the overdentures in all patients after 12 months of clinical use, dictated replacement of the wearied pink nylon inserts with new ones utilizing the insertion tool. ${ }^{[39]}$

The significant increase in the mean bone height measurements in both groups, indicating increased crestal bone resorption in the first six months compared to those measurements from six to twelve months, which might be explained by the continuous remodeling process of bone surrounding the implant resulting in bone resorption, followed by bone deposition. [40].

The crestal bone resorption around implants is a well-known phenomenon occurring mostly in the initial phase of functional implant loading and considered as an immediate bone response after insertion of the implant supported prosthesis. The mean marginal bone loss in the present study from base line to 24 months is considered within accepted permissible limits occurring with most dental implants. ${ }^{[40]}$

The placement of additional two posterior implants in the First group (Group I), was highly preferable; because, this position increased the length of antero-posterior spread (A-P distance) and hence, better load distribution with minimal bone loss compared to the Second group (Group II). ${ }^{[41]}$ In contrast to the present study, other clinical investigation reported that marginal bone level around implants supporting maxillary overdentures seems not to be affected by the number of implants used for supporting the overdentures.

Regarding changes of bone density around the implant, it was evident that there was a significant decrease of mean values of bone density at the first 6 months. This was mainly attributed to the surgical trauma during implant surgery. In addition to, the precautions given to the patient to maintain soft diet during the initial phase of treatment. ${ }^{[2]}$ 
The statistically significant increase in the bone density measurements in periods from six to twelve months, indicating favorable bone reaction to the applied forces that were within the physiologic limit tolerated by the bone and hence, favorable progress of the osseointegration process. Moreover, the proper distribution of the load in (Group I) related to the greater implant number might have enhanced the structural orientation of bone trabeculae and hence increase bone density around the implants which was clearly significant than in (Group II).

The results of the present clinical investigation were not in line with the null hypothesis previously established.

\section{CONCLUSION}

Within the limits of this clinical research study, concerning the relatively small sample size, it could be conservatively determined that:

- This study was presented to compare the impact of using six and four implants on the clinical and radiographic outcomes for an implant-assisted maxillary overdenture.

- Twenty-four patients were carefully chosen from the outpatient clinic of the Removable Prosthodontic department, Faculty of Dentistry, Cairo University, with edentulous arches. Patients were uniformly divided into two equivalent groups; First group, received an overdenture supported by six implants, while Second group obtained their overdenture supported by only four implants.

- Clinical and Radiographic outcomes of the implants supporting the overdentures had been calibrated at time of implants insertion, 6 months, 12 months, 18 months and 24 months respectively (N.B: Forcemeter measurements started at the time of overdenture insertion Not at the time of implants insertion i.e. only four readings were obtained).
- A statistically significant difference in retention values between the two groups (with the superiority of Group I) was observed throughout the whole study period.

- A statistically significant Bone height \& Bone density measurements were observed between both groups, with the predominance to Group I.

From the results of this study, the following conclusions could be achieved:

- Maxillary Overdentures supported by six implants exhibited better treatment modality than those supported by four implants, in terms of clinical as well as radiographic outcomes.

- Both modalities presented a workable treatment option for supporting a maxillary overdenture.

- More clinical investigations with larger sample sizes and over larger time scale, are still needed.

\section{CONFLICT OF INTEREST}

This clinical study was self-funded by the author, with no conflict of interest.

\section{REFERENCES}

1. Avrampou M, Mericske-Stern R, Blatz M, et al.: Virtual implant planning in the edentulous maxilla: criteria for decision making of prosthesis design. Clin Oral Impl Res 2013; 24 (Suppl. A100):152-159

2. Sanz M, Ivanoff CJ, Weingart D, et al: Clinical and radiologic outcomes after submerged and transmucosal implant placement with two-piece implants in the anterior maxilla and mandible: 3-year results of a randomized controlled clinical trial. Clin Implant Dent Relat Res 2015; $17: 234-246$

3. Andreiotelli M., Att W., Strub JR.: Prosthodontic complications with implant overdentures; a systematic literature review. Int. J. Prosthodont., 2010; 23:195-203.

4. Stoumpis C., Kohal RJ.: To splint or not to splint oral implants in the implant-supported overdenture therapy? A systematic literature review. J. Oral Rehabil. 2011; 38:857-869. 
5. Papaspyridakos P., Chen CJ., Singh M., Weber HP., Gallucci GO.: Success criteria in implant dentistry; a systematic review. J. Dent. Res. 2012; 91:242-248.

6. Kohen J, Matalon S, Block J, et al.: Effect of implant insertion and loading protocol on long-term stability and crestal bone loss: a comparative study. J Prosthet Dent 2016; 115:697-702

7. Clelland N, Chaudhry J, Rashid RG, McGlumphy E.: Split-mouth comparison of splinted and non-splinted prostheses on short implants: 3-year results. Int. J Oral Maxillofac Implants. 2016;31(5):1135-1141.

8. Vervaeke S, Collaert B, De Bruyn H.: Immediate loading of implants in the maxilla: survival and bone loss after at least 2 years in function. Int J Oral Maxillofac Implants. 2013;28(1):216-221.

9. Klemetti E.: Is there a certain number of implants needed to retain an overdenture? J. Oral. Rehab. 2008; 35 (Suppl 1):80-84.

10. Al-Zubeidi MI., Alsabeeha NH., Thomson WM., Payne AG.: Patient satisfaction with maxillary 3-implant overdentures using different attachment systems opposing mandibular 2-implant overdentures. Clin. Implant Dent. Rel. Res. 2012; 14 (Suppl 1): e11-e19.

11. Guljé FL, Raghoebar GM, Vissink A, Meijer HJ.: Single crowns in the resorbed posterior maxilla supported by either 6-mm implants or by 11-mm implants combined with sinus floor elevation surgery: a 1-year randomized controlled trial. Eur J Oral Implantol. 2014;7(3):247-255.

12. Guljé F, Abrahamsson I, Chen S, Stanford C, Zadeh H, Palmer R.: Implants of $6 \mathrm{~mm}$ vs. $11 \mathrm{~mm}$ lengths in the posterior maxilla and mandible: a 1-year multicenter randomized controlled trial. Clin Oral Implants Res. 2013;24(12):1325-1331.

13. Al Amri MD, Abduljabbar TS, Al-Kheraif AA, et al.: Comparison of clinical and radiographic status around dental implants placed in patients with and without prediabetes: 1-year follow-up outcomes. Clin Oral Implants Res 2017; 28:231-235

14. Brennan M., Houston F., O’Sullivan M., O’Connell B.: Patient satisfaction and oral health-related quality of life outcomes of implant overdentures and fixed complete dentures. Int. J. Oral Maxillofac Impl. 2010; 25:791-800.

15. Al Amri MD, Abduljabbar TS: Comparison of clinical and radiographic status of platform-switched implants placed in patients with and without type 2 diabetes mellitus: a 24-month follow-up longitudinal study. Clin Oral Implants Res2017; 28:226-230

16. Fromentin O., Lassauzay C., Abi Nader S., Feine J., de Albuquerque Junior RF.: Testing the retention of attachments for implant overdentures - validation of an original force measurement system. J. Oral Rehab. 2010; 37:54-62.

17. Al Amri MD: Crestal bone loss around submerged and non-submerged dental implants: a systematic review. J Prosthet Dent 2016; 115:564-570.e1

18. Calvo-Guirado JL, Perez-Albacete C, Aguilar-Salvatierra A, et al.: Narrow- versus mini-implants at crestal and subcrestal bone levels. Experimental study in beagle dogs at three months. Clin Oral Investig 2015; 19:1363-1369

19. Hasan, I, Dominiak M, Blaszczyszyn A, Bourauel C, Gedrange T, Heinemann F.: Radiographic evaluation of bone density around immediately loaded implants. Ann Anat. 2015; 199:52-57.

20. Tatli U, Salimov F, Kürkcü M, Akoğlan M, Kurtoğlu C. Does cone beam computed tomography-derived bone density give predictable data about stability changes of immediately loaded implants? a 1-year resonance frequency follow-up study. J Craniofac. Surg. 2014; 25:293-299.

21. Aziz AS, Kalekar MG, Suryakar AN, et al: Assessment of some biochemical oxidative stress markers in male smokers with chronic periodontitis. Indian J Clin Biochem. 2013; 28:374-380

22. Bidra AS: Three-dimensional esthetic analysis in treatment planning for implant-supported fixed prosthesis in the edentulous maxilla: review of the esthetics literature. J. Esthet. Rest. Dent. 2011; 23:219-236.

23. Rohlin M., Nilner K., Davidson T., et al.: Treatment of adult patients with edentulous arches: a systematic review. Int. J. Prosthod. 2012;.25:553-567.

24. Sadowsky SJ., Bedrossian E.: Evidenced-based criteria for differential treatment planning of implant restorations for the partially edentulous patient. J. Prosthod. 2013; 22:319-329.

25. Al Amri MD, Kellesarian SV, Al-Kheraif AA, et al: Effect of oral hygiene maintenance on HbAlc levels and periimplant parameters around immediately-loaded dental implants placed in type-2 diabetic patients: 2 years followup. Clin Oral Implants Res 2016; 27:1439-1443

26. Fortin T., Camby E., Alik M., Isidori M., et al: Panoramic images versus three-dimensional planning software for 
oral implant planning in atrophied posterior maxillary; a clinical radiological study. Clin. Impl. Dent. Rel. Res. 2013; 15:198-204.

27. Esposito M, Grusovin MG, Maghaireh H, Worthington HV.: Interventions for replacing missing teeth: different times for loading dental implants. Cochrane Database Syst. Rev. 2013;3:CD003878.

28. Kutan E, Bolukbasi N, Yildirim-Ondur E, et al.: Clinical and radiographic evaluation of marginal bone changes around platform-switching implants placed in crestal or subcrestal positions: a randomized controlled clinical trial. Clin Implant Dent Relat. Res 2015;17(Suppl 2): e364-375

29. Katsoulis J., Brunner A., Mericske-Stern R.: Maintenance of implant-supported maxillary prostheses: a 2-year controlled clinical trial. Int. J. Oral Maxillofac. Impl. 2011; 26:648-656.

30. Aimetti M, Ferrarotti F, Mariani GM, et al.: Soft tissue and crestal bone changes around implants with platformswitched abutments placed non-submerged at sub-crestal position: a 2-year clinical and radiographic evaluation. Int. J Oral Maxillofac Implants 2015; 30:1369-1377

31. Chrcanovic BR, Albrektsson T, Wennerberg A: Immediately loaded non-submerged versus delayed loaded submerged dental implants: a meta-analysis. Int. J Oral Maxillofac Surg. 2015; 44:493-506

32. Becker W.: Osseointegration: have we tinkered with the process too much? Clin. Impl. Dent. Rel. Res. 2012; 14 (6):779-780.

33. Kheur MG, Sandhu R, Kheur S, Le B, Lakha T.: Reliability of resonance frequency analysis as an indicator of implant micromotion: an in vitro study. Implant Dent. 2016; 25:783-788.

34. Huang H, Wismeijer D, Shao X, Wu G.: Mathematical evaluation of the influence of multiple factors on implant stability quotient values in clinical practice: a retrospective study. Ther Clin Risk Manag. 2016; 12:1525-1532.
35. Kim SJ, Ribeiro AL, Atlas AM, et al.: Resonance frequency analysis as a predictor of early implant failure in the partially edentulous posterior maxilla following immediate nonfunctional loading or delayed loading with single unit restorations. Clin Oral Implants Res. 2015; 26:183-190.

36. Slot W., Raghoebar GM., Vissink A., et al:: Maxillary overdentures supported by four or six implants in the anterior region; 1-year results from a randomized controlled trial. J. Clin. Period. 2013; 40:303-310.

37. Slot W., Raghoebar GM., Vissink A., et al.: A systematic review of implant-supported maxillary overdentures after a mean observation period of at least 1 year. J Clin. Period. 2010; 37:98-110.

38. Grassi R., Rebaudi A., Trisi P., Covani U., Barone A.: Bone loss around immediately loaded transitional implants: histologic and micro-computed tomographic analysis--a case report. Int. J. Period. Rest. Dent. 2012; 32 (6):195-203.

39. Trisi P, Berardini M, Falco A, Podaliri Vulpiani M.: Validation of value of actual micromotion as a direct measure of implant micromobility after healing (secondary implant stability). An in vivo histologic and biomechanical study. Clin Oral Implants Res. 2016; 27:1423-1430.

40. Osman RB., Payne AG., Ma S.: Prosthodontic maintenance of maxillary implant overdentures: a systematic literature review. Int. J. Prosth. 2012; 25:381-391.

41. Gobbato L., Avila-Ortiz G., Sohrabi K., et al.: The effect of keratinized mucosa width on peri-implant health: A systematic review. Int. J. Oral Maxillofac. Impl. 2013; 28:1536-1545.

42. Cesaretti G, Botticelli D, Renzi A, Rossi M, Rossi R, Lang NP.: Radiographic evaluation of immediately loaded implants supporting 2-3 units fixed bridges in the posterior maxilla: a 3-year follow-up prospective randomized controlled multicenter clinical study. Clin Oral Implants Res. 2016; 27:399-405. 